\title{
A APLICABILIDADE DAS TECNOLOGIAS DA INFORMAÇÃO E COMUNICAÇÃO NO ENSINO BÁSICO
}

\section{ARTIGO ORIGINAL}

SILVA, Rondinelli de Carvalho ${ }^{1}$

SÁ, Gilmara Benício de ${ }^{2}$

DANOWSKI, Huber Danúbio Correia ${ }^{3}$

BEUTTENMÜLLER, Zailton Frederico ${ }^{4}$

ALVES, José Jakson Amancio ${ }^{5}$

SILVA, Rondinelli de Carvalho. Et al. A aplicabilidade das Tecnologias da Informação e Comunicação no Ensino Básico. Revista Científica Multidisciplinar Núcleo do Conhecimento. Ano 05, Ed. 05, Vol. 09, pp. 05-13. Maio de 2020. ISSN: 2448-0959, Link de

1 Mestrado em Ciências da educação, Especialização em História do Brasil e Licenciado em História.

2 Mestrado em Ciências da Educação, Especialização em Educação Infantil e Licenciada em Pedagogia.

3 Mestrado em Ciências da educação, Especialização em História do Brasil e Licenciado em História e Pedagogia.

${ }^{4}$ Mestrado em Ciências da educação, Especialização em Gestão Pública e Bacharel em Biblioteconomia.

${ }^{5}$ Doutorado em Recursos Naturais. Mestrado em Meteorologia. Especialização em Especialização em Geografia do Nordeste. Graduação em Licenciatura Plena em Geografia. 
acesso: https://www.nucleodoconhecimento.com.br/educacao/aplicabilidade-das$\underline{\text { tecnologias }}$

\section{RESUMO}

A partir do século $X X I$, com a democratização da internet no Brasil, surgiram ferramentas educativas que proporcionaram uma maior e ágil massificação do acesso à informação digital. Mesmo diante deste cenário favorável, ainda enfrentamos, até os dias atuais, dificuldades na implementação destas novas tecnologias na educação básica do ensino público. Diante desta constatação, este trabalho tem como objetivo examinar a aplicabilidade das Tecnologias de Informação e Comunicação - TICs no processo de ensino-aprendizagem. Trata-se de um trabalho descritivo, de cunho bibliográfico, visando apresentar conceitos relacionados a nova metodologia adotada no ensino. Atinamos que as TICs, em parceria com à educação básica, podem acrescentar valores, visando uma aprendizagem significativa dos discentes, porém, mesmo com esta qualidade, existem inúmeros obstáculos que dificultam sua utilização pelos docentes nas escolas públicas. Observou-se, também, aquisições investigativas que apresentassem um breve relato do inserimento das desiguais tecnologias em destaque na educação do Brasil e a maneira como ela é utilizada em nossa contemporaneidade. O propósito de alcançar e explorar os prováveis obstáculos encontrados por docentes da segunda fase do Ensino Fundamental que atuam na escola pública no usufruto das TICs no processo ensino-aprendizagem. O professor precisa estar motivado e valorizado no uso das novas tecnologias, acreditando na sua aplicabilidade e efetivação.

Palavras-Chave: Formação do professor, Tecnologia e Inclusão.

\section{INTRODUÇÃO}

Com as novas tecnologias empregadas ao conhecimento, a educação começou a dar passos cada vez mais evolutivos a partir da primeira década do século XXI. A efetuação das novas tecnologias nas unidades de ensino vem facilitando 0 
aprendizado e consequentemente uma troca de informações muito mais veloz dando dinamismo ao processo de ensino. Por outro lado, percebemos uma falta de preparo por parte da área institucional que se limita a velhas práticas metodológicas colocadas pela metodologia de ensino público.

O acesso as novas tecnologias carecem de reformas nas escolas públicas do Brasil e na prática dos docentes nos dias atuais mediante implementação democrática.

As tecnologias da informação e comunicação podem dar entrada a junção instrutiva, aparenta haver certo desalinho vigente na realidade vivenciada por educadores e educandos nas escolas públicas do Brasil para a sua anexação nos saberes escolares desde o entrave burocrático a uma ausência de prioridades. Para isso "ainda existem muitas barreiras a serem superadas para a integração efetiva das TICs aos processos pedagógicos, que vão além das dificuldades associadas a questões de infraestrutura das TICs nas escolas." (BARBOSA, 2014, p. 28).

Deste modo, necessita-se que os educadores tomem conhecimento das transformações nas práticas educacionais de forma a suplantarem possíveis bloqueios que a eles se apresentam na didática de ensino.

\section{FUNDAMENTAÇÃO TEÓRICA}

Com as alterações nas relações do sistema de ensino brasileiro e a ascensão tecnológica ao longo do século XXI, a sociedade começou a reivindicar da escola com uma maior participação efetiva na educação das novas gerações ao que se compete a inserção e uso das TICs. A escola quanto espaço formador de base precisa acompanhar tais transmutações, sabendo que a notícia vem sendo transcorrido muito aceleradamente e que os envolvidos no procedimento docentes e discentes requerem estar entreligados as novas tecnologias de maneira objetiva. A escola pertencendo a um lugar de construção e sociabilização do conhecimento, não apenas prepara o sujeito para a permanência no ambiente escolar, mas também para o espaço de trabalho, e para a vivência social. Selva Guimarães Fonseca (2006) especifica a escola como um ambiente pedagógico de produção de maneiras diante do saber 
formal, pela ação que a mesma executa no processo de aprendizagem por meio da coletividade. Portanto, cabe ao educador, produzir seus planos pedagógicos com base nesse conceito de escola, objetivando a prosperidade da aprendizagem dos educandos.

As modernas tecnologias da informação vêm mudando-se por um processo de transformação em nosso corpo social como todo, enfrentam a escola e a possibilidade do seu uso oportuno na educação dependendo essencialmente do preparo do incluindo no seu currículo. Marisa Sampaio e Lígia Leite (2010, p.15) chamam a atenção para o seguinte entendimento:

Preparo do professor que deverá atuar em ambientes informatizados de aprendizagem. A formação adequada dos professores para o trato com as novas tecnologias da informação é uma urgência e um desafio principalmente às universidades, por suas licenciaturas. Pensar sobre essa (formação do educador) e outras questões de ordem metodológica é um desafio lançado aos próprios professores que constroem, no seu dia-a-dia, a educação do próximo milênio.

A escola deve inserir as mídias eletrônicas como um acessório de trabalho tão importante quanto o livro didático, através dos programas educativos vigente e buscando também nas políticas educacionais, subsídios efetivos para o apoio de tais propostas, como é o caso dos Parâmetros Curriculares Nacionais, que traz em seu campo a sugestão de alternância e de quebra de moldes. Dentre as inúmeros concepções inovadoras da educação, a interatividade e as tecnologias estão interligadas. É o ato de que a ideia de rede como representação do entendimento traz um amparo muito significativo para a compreensão das convicções articuladas em sala de aula e para outras interconexões que se estabelecerão adiante. $\mathrm{O}$ uso das novas tecnologias fascina a todos, apesar disso verifica-se que, a qualidade dos docentes nem todos estão adaptados a essa nova tecnologia diante de uma ausência de valorização do profissional no ensino público. 
As imagens e a música quando bem norteada abre os caminhos do utópico e da criatividade do educando, sem contar os proveitos de uma aula prática e movimentada para os dois lados. Tendo em mente que desde o momento onde o educador alcançou o seu ápice proposto na construção do conhecimento inevitavelmente o aprendiz também acertara com mais disposição as suas metas planejadas. seguindo da hipótese de que o docente é incessantemente um praticante, que deve estar sempre lendo, atualizando e refletindo sobre seu costume instrutivo, aperfeiçoando e refazendo seu conhecimento, é que deduzimos a leal conveniência de análise do enunciado retratado. $O$ docente principiante deve voltar-se as pesquisas como mesmo entusiasmo de quando era discente. Citando Freire, somos eternos aprendizes!

A reformulação curricular é um tema abordado na discussão sobre a instrução, segundo Circe Bittencourt (2005, p. 99):

As transformações no ensino de história podem ser identificadas mediante a análise de várias propostas curriculares elaboradas a partir de 1980 pelos Estados e municípios e pelos Parâmetros Curriculares Nacionais, produzidos pelo poder federal na segunda metade da década de 90. Nos últimos dez anos têm surgido uma variedade de propostas que almejam proporcionar um ensino de história mais significativo para a geração do mundo tecnológico, com seus ritmos diversos de apreensão do presente e seu intenso consumismo, o qual desenvolve, no público escolar, expectativas utilitárias muito acentuadas.

O ideal de um currículo acadêmico que contemple o uso das TICs já existe na discussão teórica sobre a prática do ensino, porém necessitam de adequações que coloquem em prática essas propostas saindo do plano teórico para o definido dando Ihe oportunidades para efetiva participação.

No caso desta inquirição utilizamos um questionamento apreciativo, pois interessava atingir no enquadramento como os docentes estavam empregando com as TICs. Segundo Moreira e Caleffe (2006, p. 61) "a interpretação é a busca de perspectivas 
seguras em insights particulares. Ela pode oferecer possibilidades, mas não certezas sobre o que poderá ser o resultado de acontecimentos futuros" desse modo, a presente pesquisa pretende apresentar dentro do universo pesquisado, alguns caminhos de compreensão sabendo que eles não representam a totalidade dos problemas que envolvem a relação entre TICs e educação.

É importante lembrar que a história do ser humano e suas relações ao meio têm sido essencial ao desenvolvimento da humanidade, e nesse decorrer evolutivo surge o mérito de adequações e mudanças. A era da interatividade mudou de maneira drástica a relação de viver da população. De acordo com Vieira Pinto (2005, p. 792), "a função da tecnologia coincide com a promoção da liberdade pelas perspectivas que abre ao homem para refletir sobre si, seus problemas e exigências".

Observa-se, o uso da TICs na educação leva em uma ampla interatividade e vínculo a aprendizagem em consonância com os resultados. A informática na escola pública não deve se limitar a disciplina, e sim necessita ser divulgada como uma ferramenta, um complemento para o docente na integração de seus conteúdos, seu propósito não se cessa nos métodos de digitações e em conceitos básicos de funcionamento da interatividade, mas de uma sucessão de hipóteses que deve ser explorado por discentes e docentes.

Vieira (2011) interpreta duas possibilidades para se fazer uso das TICs: a primeira é de que o docente deve-se fazer uso deste para instruir os discentes e a segunda possibilidade é que o docente deve criar subsídios para que os discentes representem seus pensamentos, reconstrua-os e materialize-os, através de novas dicções, nesse processo o discente é desafiado a modificar as informações em conhecimentos práticos para seu saber.

[...] a implantação da informática como auxiliar do processo de construção do conhecimento implica mudanças na escola que vão além da formação do professor. É necessário que todos os segmentos da escola - alunos, professores, administradores e comunidades de pais - 
estejam preparados e suportem as mudanças educacionais necessárias para a formação de um novo profissional. Nesse sentido, a informática é um dos elementos que deverão fazer parte da mudança, porém essa mudança é mais profunda do que simplesmente montar laboratórios de computadores na escola e formar professores para utilização dos mesmos. (VIERIA, 2011, p. 4)

A autora deixa explicito que a implementação de centros de informática nas escolas não é suficiente para que a educação no Brasil dê um salto na qualidade, mas carecem de uma globalização que se compete as políticas educacionais no âmbito externo. A velocidade da informação está cada vez mais conectada com o mundo e a escola necessita está inserida como protagonista ao presente e futuro. O exemplo finlandês deixa evidente a inserção do professor como agente permanente:

Certamente, esse tipo de abordagem é favorecido por um contexto em que a qualidade da formação docente e o prestígio social dos professores estão consolidados. Mesmo não sendo essa a realidade brasileira, a centralidade dos profissionais da educação e a compreensão do processo de ensino-aprendizagem como um processo criativo por natureza, em que devem predominar relações de compromisso e confiança mútua, são aspectos importantes a serem considerados em nosso meio. (BRITTO, 2013, p. 20)

A valorização do profissional da educação necessita estar implementada em uma agenda permanente no Brasil, pois só assim se conseguirá construir alicerces para uma educação básica no âmbito das novas tecnologias.

No momento presente, o mundo tem a sua escolha múltipla inovações tecnológicas para se usar no ambiente escolar, o que corresponde com uma comunidade pautada na indicação e na competência, pois através desses meios temos a possibilidade online de ter acesso a todo tipo de informação, independentemente do local em que nos frequentamos e do momento. A atualização tecnológica ocasionou enormes 
vantagens em adiantamento científico, educacional, comunicação, entretenimento, processamento de dados e conhecimento. Segundo Cysneiros (1999, p.20):

Embora devamos perseguir o ideal de uma aprendizagem estimulante e auto motivadora em salas de aulas ricas em recursos e com respeito à individualidade e espontaneidade do aprendiz - sabemos que além do prazer da descoberta e da criação, é necessário disciplina, persistência, suor, tolerância à frustração, aspectos do cotidiano do aprender e do educar que não serão eliminados por computadores. (CYSNEIROS,1999, p.20)

Sabemos que, o intermédio das ferramentas tecnológicas intermédia a aprendizagem e gera uma evolução no processo do conhecimento. Se antes a escola física era o único espaço, atualmente as novas tecnologias mostram que vieram para revolucionar de forma permanente.

\section{CONSIDERAÇÕES FINAIS}

O presente artigo analisou teoricamente a aplicabilidade das TICs e suas dificuldades de utilização, na prática do ensino diante da literatura exposta.

Ao investigarmos as dificuldades que se apresentam aos professores das escolas públicas no que se refere à utilização das TICs no processo ensino-aprendizagem, podemos perceber que a sua união às práticas pedagógicas está prematura de atingir o nível de qualidade preconizado pela legislação vigente. Há que se reorganizar os programas educacionais de implantação dos equipamentos nas escolas públicas buscando garantir a sua permanência e aplicabilidade, em termos de acesso a serviços de alta velocidade, qualidade didática (no caso de áudio visual e jogos), como também a implementação de rede na mobilidade, proporcionando a relação de um computador para cada discente e docente.

A razão essencial para conquistarmos alçar-se os obstáculos tecnológicos no ensino deve-se à produção continuada de professores com implementação da valorização 
profissional para utilização das diferentes TICs em sua prática pedagógica. Estes cursos podem ser realizados tanto na modalidade presencial como também na modalidade à distância, em complemento as formações continuadas.

Diante de uma pandemia a nível mundial, a exemplo do COVID-19, mostrou-se que o ensino público precisa estar preparado para as interrupções do espaço físico da escola, sendo necessário dar-lhes condições ao que se compete ao ensinoaprendizagem aos discentes e a possibilidade de não interrupção das aulas. Novas discussões e implementações, de maneira efetiva, necessitam estarem presentes nos debates em nossa sociedade.

O profissional da educação carece de suporte e condições para uma efetiva aplicabilidade das TICs em seu ambiente de trabalho no que tratam do tema da inserção das tecnologias na educação com a expectativa de entrelaçar os educadores na implementação das mesmas no processo ensino-aprendizagem.

\section{REFERÊNCIAS}

BARBOSA A. F. (coord). Pesquisa sobre o uso das tecnologias de informação e comunicação nas escolas brasileiras: TIC Educação 2013. 2014. Disponível em: <http://www.cetic.br/media/docs/publicacoes/2/TIC_DOM_EMP_2013_livro_eletronic o.pdf>. Acesso em 13/09/2019.

BITTENCOURT, Circe Maria Fernandes. Ensino de história: Fundamentos e métodos- São Paulo: Cortez, 2004(Coleção docência em formação).

BRITTO, Tatiana Feitosa de. 'O que é que a Finlândia tem?' Notas sobre um sistema educacional de alto desempenho. Disponível em: < http://www12.senado.gov.br/publicacoes/estudoslegislativos/tipos-de-estudos/textospara-discussao/td-129-2018o-que-e-que-a-finlandia-tem-2019 notas-sobre-umsistema-educacional-de-alto-desempenho>. Acesso em 21/04/2020. 
CYSNEIROS, P. G. Novas Tecnologias na sala de aula: melhoria do ensino ou inovação conservadora? Informática Educativa, Uniandes-LIDIE, v. 12, n. 1, p. 1124, 1999.

FONSECA, Selva Guimarães. Didática e prática de ensino de história: Experiências, reflexões e aprendizados. 5 ed. Campinas, SP: Papirus, 2006 (Coleção Magistério: Formação do Trabalho Pedagógico).

MOREIRA, Erivelto; CALEFFE, Luiz Gonzaga. Metodologia da pesquisa para o professor pesquisador. Rio de Janeiro: DP\&A, 2006.

PINTO, Álvaro Vieira. O conceito de tecnologia. Rio de Janeiro: Contraponto, 2005, $1 \mathrm{v}$.

SAMPAIO, Marisa Narcizo. LEITE, Lígia Silva. Alfabetização tecnológica do professor. Ed. Petrópolis, RJ: Vozes, 2010.

VALENTE, José Armando. Informática na educação no Brasil: análise e contextualização histórica. In: VALENTE, José Armando (org.). O Computador na Sociedade do Conhecimento. Campinas: UNICAMP / NIED, 1999, pp. 01-27.

VIEIRA, Rosângela Souza. O papel das tecnologias da informação e comunicação na educação: um estudo sobre a percepção do professor/aluno. Formoso - BA: Universidade Federal do Vale do São Francisco (UNIVASF), 2011. v. 10.

Enviado: Abril, 2020.

Aprovado: Maio, 2020. 